\title{
BMJ Open Is cost-related non-collection of prescriptions associated with a reduction in health? Findings from a large-scale longitudinal study of New Zealand adults
}

\author{
Santosh Jatrana, ${ }^{1}$ Ken Richardson, ${ }^{2}$ Pauline Norris, ${ }^{3}$ Peter Crampton ${ }^{4}$
}

To cite: Jatrana $S$,

Richardson K, Norris $\mathrm{P}$, et al. Is cost-related non-collection of prescriptions associated with a reduction in health? Findings from a large-scale longitudinal study of New Zealand adults. BMJ Open 2015;5:e007781. doi:10.1136/bmjopen-2015007781

- Prepublication history for this paper is available online. To view these files please visit the journal online (http://dx.doi.org/10.1136/ bmjopen-2015-007781).

Received 27 January 2015 Revised 4 August 2015 Accepted 17 September 2015

CrossMark

For numbered affiliations see end of article.

\section{Correspondence to}

Dr Santosh Jatrana; santosh.jatrana@deakin.edu. $\mathrm{au}$

\section{ABSTRACT}

Objective: To investigate whether cost-related noncollection of prescription medication is associated with a decline in health.

Settings: New Zealand Survey of Family, Income and Employment (SoFIE)-Health.

Participants: Data from 17363 participants with at least two observations in three waves (2004-2005, 2006-2007, 2008-2009) of a panel study were analysed using fixed effects regression modelling.

Primary outcome measures: Self-rated health (SRH), physical health (PCS) and mental health scores (MCS) were the health measures used in this study.

Results: After adjusting for time-varying confounders, non-collection of prescription items was associated with a $0.11(95 \% \mathrm{Cl} 0.07$ to 0.15$)$ unit worsening in $\mathrm{SRH}$, a $1.00(95 \% \mathrm{Cl} 0.61$ to 1.40$)$ unit decline in PCS and a $1.69(95 \% \mathrm{Cl} 1.19$ to 2.18$)$ unit decline in MCS. The interaction of the main exposure with gender was significant for SRH and MCS. Non-collection of prescription items was associated with a decline in SRH of $0.18(95 \% \mathrm{Cl} 0.11$ to 0.25$)$ units for males and $0.08(95 \% \mathrm{Cl} 0.03$ to 0.13$)$ units for females, and a decrease in MCS of $2.55(95 \% \mathrm{Cl} 1.67$ to 3.42$)$ and $1.29(95 \% \mathrm{Cl} 0.70$ to 1.89$)$ units for males and females, respectively. The interaction of the main exposure with age was significant for SRH. For respondents aged 15-24 and 25-64 years, noncollection of prescription items was associated with a decline in SRH of $0.12(95 \% \mathrm{Cl} 0.03$ to 0.21$)$ and 0.12 $(95 \% \mathrm{Cl} 0.07$ to 0.17$)$ units, respectively, but for respondents aged 65 years and over, non-collection of prescription items had no significant effect on SRH.

Conclusion: Our results show that those who do not collect prescription medications because of cost have an increased risk of a subsequent decline in health.

\section{INTRODUCTION}

Since the Rand study in the 1980s, it has been clear that prices significantly affect consumption of healthcare, including medicines, ${ }^{1}$ even in countries that have generous drug

\section{Strengths and limitations of this study}

- A panel study design and a large sample of the adult population.

- Use of fixed effects regression, which controls for all unmeasured time-invariant and known time-varying confounders.

- Use of multiple measures of health outcome.

- Violation of fixed effects assumptions and measurement errors in self-reported health measures

- Residual selection bias due to attrition of respondents from the survey.

coverage. ${ }^{2-5}$ Increasing charges for prescription medicines and/or cost barriers to collecting prescription medication have been associated with lower rates of use, ${ }^{6-9}$ lower prescription medicine compliance,${ }^{6}$ more frequent discontinuation ${ }^{6}$ and increased use of health services among some groups. ${ }^{6} 8$

Less is known about the extent to which cost-related restriction of medications is associated with adverse health outcomes. The evidence is limited to cross-sectional studies of selected groups, such as elderly persons and welfare recipients, ${ }^{8}$ the elderly, ${ }^{10}$ adults with disabilities, ${ }^{11}$ older adults with diabetes, ${ }^{12}{ }^{13}$ Medicare beneficiaries ${ }^{14}$ and indigent patients with heart disease. ${ }^{15}$ Since these are cross-sectional in design, they are susceptible to unmeasured confounding bias. Developing a better understanding of the impact of non-collection or deferral of prescription medication requires longitudinal data on prescription medication deferral and health. One of the few studies to explore the longitudinal relationship between costrelated deferral of prescription medicines and health showed that, for middle-aged and elderly Americans, deferral led to poorer self-rated health (SRH) and higher rates of 
some cardiovascular events among those with existing cardiovascular disease. ${ }^{16}$ This group was also more likely to be hospitalised within 2 years of reported prescription deferral. ${ }^{17}$ However, Heisler et $a l^{16}$ focused on adults aged 51-61 and 70 years or older, and had a relatively short follow-up period (2-3 years). Their study also had methodological limitations, such as not accounting for time-invariant unmeasured confounding or serial correlation.

Apart from being cross-sectional, much of the research on the impact of prescription charges has been carried out in the USA, where people pay large amounts for prescription medicines, particularly if they are uninsured or underinsured. Even people covered by the Medicare Prescription Drug Benefit (known as Part D) pay significant amounts for prescription medicines and there is a coverage gap. ${ }^{18}$ In countries with public health systems, prescription charges are generally lower, and those on low incomes and/or with high healthcare needs are often exempted. ${ }^{4}$ In the UK, prescriptions are free of charge in Wales, Ireland and Scotland, whereas in England, people under 16 or over 60 years of age, or those dependent on government benefits, receive free prescriptions. ${ }^{19}{ }^{20}$ In New Zealand, prescription charges are low $(\mathrm{NZ} \$ 3.00$ (£1.46) during the study and currently NZ\$5.00 (£2.43) per item) but only children under 6 years of age are currently exempted. There is evidence that even these low charges lead to cost-related defer$\mathrm{ral},{ }^{21}$ but it is not known whether this deferral leads to poor health outcomes. Although it is likely that increases in relatively high initial prices (such as in the USA) could lead to people deferring medicines that are crucial for maintaining health, there is no evidence about whether increases in relatively low prices might have the same effect.

In this study, we examine the association of costrelated non-collection of prescription medication with health status, using a national panel study of adult New Zealanders. We used fixed effects analyses that remove all observed and unobserved time-invariant confounding, allowing a more robust assessment of causal associations than is possible with non-repeated-measures data. We hypothesise that after adjusting for demographic, socioeconomic and behavioural factors, and accounting for unmeasured time-invariant confounders (unobserved fixed characteristics of individuals such as intelligence or beliefs that are likely to be associated with both deferral and health), those who do not collect one or more prescription medications would be more likely to experience a decline in self-rated, physical and mental health.

\section{METHODS}

Data

This research used data from three waves of the SoFIE-Health survey, which is an add-on to the Statistics New Zealand Survey of Family, Income and Employment
SoFIE V.2, Waves $1-7 .^{22}$ SoFIE is an 8 year (2002-2010) longitudinal household panel survey. Computer-assisted face-to-face interviews were used to collect data annually on income levels and sources, and on the major influences on income such as employment and education, household and family status, demographic factors and health status.

The population covered by SoFIE includes those living in private dwellings, and excludes people living in institutions or establishments such as boarding houses and rest homes. The initial SoFIE sample comprised approximately 11500 responding private households (response rate $83 \%$ ) with 22200 adults (aged 15 years and above) responding in wave 1 , reducing to just over 20000 in wave 2 (91\% of wave 1 responders) and over 19000 in wave 3 ( $86 \%$ of wave 1 responders). By wave 7 , there were almost 17000 (76\% of wave 1) from the original sample still participating. Higher rates of attrition occurred in youth, ethnic minorities, and people on lower income and reporting poor health. ${ }^{23}$ On average, 17377 respondents contributed information to this analysis from at least two waves.

The SoFIE-Health add-on is comprised of $20 \mathrm{~min}$ of questionnaire time in waves 3 (2004-2005), 5 (20062007) and 7 (2008-2009), in the following health-related domains: SF-36 (Short-Form health survey), Kessler-10 (K-10), perceived stress, ${ }^{24}$ chronic conditions (heart disease, diabetes and injury-related disability), tobacco smoking, alcohol consumption, access and continuity of primary health care and an individual socioeconomic deprivation score.

\section{Measures}

The main exposure, not collecting a prescription, was measured by the following question: "In the past 12 months, have there been any times when a doctor gave you a prescription, but you did not collect one or more of these items because you could not afford the cost? If yes, how many times have you done this in the last 12 months?". We dichotomised responses into collection/non-collection (or not deferred/deferred) for each of waves 3,5 and 7 .

The three health outcome measures used in this study are all derived from the SF-36 questionnaire. The SF-36 is one of the most widely used self-completion measures of health status, ${ }^{25}$ has been validated for the detection of changes in health over time ${ }^{26}$ and is considered to be reliable for use in the NZ population. ${ }^{27}$ It consists of 36 questions about the health-related quality of life of respondents. These are formed into eight domains of health, which are then used to create two psychometrically-based physical and mental health summary measures: the Physical Component Summary (PCS) and the Mental Component Summary (MCS) score. $^{28}$ The PCS and MCS vary between 0 (worst health) and 100 (best health) and are standardised to the NZ population, with a mean of 50 and a SD of 10 . Both PCS and MCS were modelled as continuous 
outcomes in regression analyses. A score of 100 in physical functioning indicates an ability to perform all activities without limitations due to health; whereas a score of 100 in mental health indicates an ability to function without personal or emotional problems. Global SRH was based on the question: "In general, would you say your health is: excellent, very good, good, fair, or poor?". In this study, SRH was coded to have values between 1 (excellent health) and 5 (poor health), and, for consistency with PCS and MCS, was also modelled as a continuous variable.

Time-varying confounders measured at each wave were labour force status, marital status, family structure, NZ Deprivation Index 2001, a measure of small area deprivation, categorised into quintiles, where quintile 5 corresponds to high deprivation, ${ }^{29}$ wave (accounting for the effect of time) and NZiDep, a measure of individual deprivation. ${ }^{30}$

Also used in the analysis were the time-invariant covariates age (at first interview), sex and ethnicity. The ethnicity variable was constructed using a 'prioritised' definition. Each respondent was assigned to a mutually exclusive ethnic group by means of a prioritisation system commonly used in New Zealand: Māori (the indigenous people of New Zealand), if any of the responses to self-identified ethnicity was Māori; Pacific, if any one response was Pacific but not Māori; Asian, if any one response was Asian but not Mãori/Pacific; the remainder non-Māori non-Pacific non-Asian (nMnPnA; mostly New Zealanders of European descent, but, strictly speaking, not an ethnic group). The reference group was nMnPnA. Early adulthood is a time of important transitions and the same is true of the period postretirement. Thus the age covariate was categorised into those under 25 years of age, those between 25-65 years, and those aged 65 years or above, to see whether these life-course events impacted on the association between noncollection of prescriptions and health.

\section{Analyses}

Analyses were conducted on an unbalanced panel of eligible wave 1 respondents $(17677)$ who responded in at least 2 of waves 3,5 or 7 , and were aged over 15 years. We hypothesised that the health of those who defer paying for prescription medication would get worse, and to determine if this was the case, we computed means and SDs of health outcomes for respondents who did not collect a prescription in at least one of 2 or 3 waves. Transition probabilities for prescription deferral averaged over waves 3,5 and 7 were computed to show the typical proportion of SoFIE respondents that changed prescription collection status between waves.

We modelled health outcomes using a linear fixed effects model. Such models eliminate variables representing time-invariant unobserved confounding, modelled as a set of fixed parameters (one for each respondent), by mean differencing. ${ }^{31}{ }^{32}$ Parameter estimates can be interpreted as the response to a 1 unit change in exposure (continuous exposure) or relative to the reference group (categorical exposure) considered contemporaneously.

Fixed effects analysis only uses changes occurring within the same individuals over time to estimate effects and ignores observations on variables that do not change temporally. However, it is possible to fit interactions between time-varying and time-invariant variables in a fixed effects model. We tested for interactions between the exposure (prescription collection status) and age, gender, ethnicity, individual deprivation, chronic disease/comorbidity status and number of longitudinal observations for each respondent, to detect differences between younger and older age groups, between men and women, between ethnic groups, between respondents who are more and less deprived, between respondents who have or do not have a chronic or comorbid disease, and between respondents with two or three responses over waves 3,5 and 7 , respectively, in the association between prescription collection status and three health outcomes.

All counts presented in this paper are rounded means of sample counts from waves 3,5 and 7, and comply with the Statistics New Zealand protocols for such quantities. Analyses were carried out within the Statistics NZ data laboratory using the $\mathrm{R}$ statistical environment (http://www.r-project.org) for statistical computation, V.3.0.1, available from the Comprehensive $\mathrm{R}$ archive Network (CRAN) website (http://cran.r-project.org). The R package $p l m$ V.1.4-0 was used to fit fixed effects models.

\section{RESULTS}

Mean values for the three health outcomes and empirical distributions of covariates are shown in tables 1 and 2 by the proportion of waves where respondents reported non-collection of a prescription item. For all outcome measures, health got worse as the proportion of waves in which non-collection of a prescription item was reported increased.

Overall, a large majority collected all prescription items (ie, did not report non-collection of any prescription items because of cost) in every wave for which they responded (table 2), but there were some variations in this pattern within covariates. For example, relatively more married respondents collected all prescription items in every wave $(92.1 \%)$ than previously married $(87.3 \%)$ or never married $(87.1 \%)$ respondents. Within levels of family status, the highest proportion of collecting all prescription items in every wave occurred for couple-only families $(95.8 \%)$ and the lowest for sole parents $(76.3 \%)$. Working and not-working respondents had similar levels of prescription item collection in every wave (about 90\%). A higher proportion of respondents from the least deprived (ie, wealthiest) areas collected all prescription items in every wave $(93.1 \%)$ than respondents from the most deprived areas $(82.5 \%)$. Similarly, a 
Table 1 Means and SEs of health outcomes where respondents did not collect one or more prescription items for financial reasons in at least one of waves 3,5 and 7, for the unbalanced SoFIE-Health panel

\begin{tabular}{|c|c|c|c|c|c|}
\hline & \multicolumn{5}{|c|}{ Proportion of waves where one or more prescription items were not collected } \\
\hline & $100 \%{ }^{*}$ & $67 \% \dagger$ & $50 \% \ddagger$ & $33 \% \S$ & 0\% \\
\hline $\mathrm{SRH}$ & $2.805(0.054)$ & $2.616(0.037)$ & $2.410(0.049)$ & $2.431(0.020)$ & $2.101(0.005)$ \\
\hline PCS & $47.501(0.520)$ & $48.131(0.370)$ & $50.370(0.465)$ & $49.675(0.194)$ & $51.536(0.044)$ \\
\hline MCS & $36.072(0.843)$ & $41.993(0.521)$ & $43.233(0.683)$ & $44.451(0.271)$ & $51.375(0.047)$ \\
\hline
\end{tabular}

higher proportion of the least individually deprived (ie, wealthiest) respondents collected all prescription items in every wave $(96.1 \%)$ than the most individually deprived $(50.5 \%)$, and relatively more respondents with degree or higher qualifications collected all prescription items in every wave $(93.8 \%)$ than those with no qualifications $(88.3 \%)$. Among the time-invariant covariates, a larger proportion of respondents older than 65 years collected all prescription items in all waves $(98 \%)$ than respondents aged 15-24 years $(88.3 \%)$, males collected all prescription items in every wave more often than females (93.4\% and 87.7\%, respectively) and Asian respondents collected all prescription items more often $(93.8 \%)$ than European (92.2\%), Māori $(80.8 \%)$ or Pacific respondents $(76.0 \%)$. Typically, these patterns reversed for respondents who did not collect prescription items in every wave, though the number of respondents tended to be small in this case.

Empirical transition probabilities between prescription collection status (collection or non-collection) in successive waves are provided in table 3. Estimates represent an average for transitions (in collection states) between waves 3 and 5 , and between waves 5 and 7 . Given those estimates, a respondent who collected all prescription items over the past 12 months before wave 3 (say) was very likely to have also collected all prescription items in the 12 months before wave 5 (average probability $97.4 \%$ ). In only $2.6 \%$ of cases did a respondent collect all prescription items in the 12 months before wave 3 but not in the 12 months before wave 5 . However, a respondent who did not collect all prescription items in the 12 months before wave 3 was more likely to collect all $(68.8 \%)$ than not collect all $(31.2 \%)$ prescription items in the 12 months before wave 5 .

Covariate effects for linear fixed effects panel models with no time-invariant interactions (ie, averaged across age, gender and ethnicity) for each health outcome are presented in table 4. Non-collection of prescription items was associated with a 0.11 (95\% CI 0.07 to 0.15 ) unit decline in SRH, a 1.00 (95\% CI 0.61 to 1.40$)$ unit decline in PCS and a 1.69 (95\% CI 1.19 to 2.18) unit decline in MCS.

For SRH, interactions of the main exposure with gender and age were significant. Allowing for those interactions, non-collection of prescription items was associated with a decline in SRH of 0.18 (95\% CI 0.11 to 0.25 ) for males and 0.08 (95\% CI 0.03 to 0.13 ) for females. For respondents aged 15-24 or 25-64 years, the effect of non-collection of prescription items on SRH was not significantly different, and was associated with a decline in SRH of 0.12 (95\% CI 0.03 to 0.21 ) and 0.12 (95\% CI 0.07 to 0.17 ) units, respectively. There was a significant difference in the association of non-collection and SRH for respondents aged 65 years and above (relative to respondents aged 15-24 years), and, as a result, non-collection of prescription items had no significant effect on SRH for this age group. The interaction of the main exposure with gender was significant for MCS. Allowing for this, non-collection of prescription items was associated with a decrease in MCS of magnitude 2.55 (95\% CI 1.67 to 3.42 ) and 1.29 (95\% CI 0.70 to 1.89) units, for males and females, respectively. Interactions of the exposure with age, gender and ethnicity were not significant for PCS, and interactions of the exposure with individual deprivation, chronic/comorbid disease status and the number of observations per respondent were not significant for any health outcome.

\section{DISCUSSION AND CONCLUSION \\ Principal findings}

First, those who did not collect prescription medications because of cost, while a relatively small proportion of the population (less than 10\%), had an increased risk of poorer health. Second, non-collection of prescription items was associated with significantly poorer SRH and MCS for males than for females. Third, non-collection of prescription items was associated with significantly poorer SRH for respondents aged 15-24 and 2564 years, but had no significant effect for respondents aged 65 years and above. Fourth, these results are net of all time-invariant confounding.

\section{Strengths and weaknesses}

The strengths of the study are the panel study design based on 18000 adults, and fixed effects analysis that removes all time invariant confounding (known or unknown) and known time-varying confounders (eg, 
Table 2 Sample counts and proportions for the number of occasions where respondents did not collect one or more prescription items for financial reasons in at least one of waves 3,5 and 7 , by demographic strata for the unbalanced SoFIE-Health panel

\begin{tabular}{|c|c|c|c|c|c|}
\hline & \multicolumn{5}{|c|}{ Proportion of waves where one or more prescription items were not collected/deferred } \\
\hline & $100 \% *$ & $67 \% \dagger$ & $50 \% \ddagger$ & $33 \% \S$ & $0 \% \rrbracket$ \\
\hline Total & $460(0.9)$ & $900(1.8)$ & $490(10.0)$ & $2885(5.9)$ & $44150(90.3)$ \\
\hline \multicolumn{6}{|l|}{ Marital status } \\
\hline Never married & $135(1.3)$ & $265(2.6)$ & $200(1.9)$ & $745(7.1)$ & $9080(87.1)$ \\
\hline Previously married & $120(1.6)$ & $195(2.7)$ & $70(1.0)$ & $535(7.4)$ & $6300(87.3)$ \\
\hline Married & $205(0.7)$ & $440(1.4)$ & $220(0.7)$ & $1600(5.1)$ & $28770(92.1)$ \\
\hline \multicolumn{6}{|l|}{ Family status } \\
\hline Couple only & $25(0.2)$ & $100(0.7)$ & $65(0.5)$ & $410(2.9)$ & $13815(95.8)$ \\
\hline One person & $110(1.1)$ & $205(2.0)$ & $120(1.1)$ & $655(6.3)$ & 9230 (89.5) \\
\hline Sole parent & 145 (3.3) & $245(5.5)$ & $125(2.8)$ & $540(12.2)$ & 3380 (76.3) \\
\hline Couple with dependants & $180(0.9)$ & $355(1.8)$ & $185(0.9)$ & $1280(6.5)$ & $17730(89.9)$ \\
\hline \multicolumn{6}{|l|}{ Labour force status } \\
\hline Working & $260(0.8)$ & $525(1.6)$ & $290(0.9)$ & $1890(5.8)$ & $29690(90.9)$ \\
\hline Not working & 205 (1.3) & $375(2.3)$ & $200(1.2)$ & $995(6.1)$ & $14460(89.1)$ \\
\hline \multicolumn{6}{|l|}{ NZ deprivation } \\
\hline Least deprived & $165(0.5)$ & $355(1.2)$ & $180(0.6)$ & $1375(4.5)$ & $28190(93.1)$ \\
\hline Medium deprived & $125(1.3)$ & $200(2.0)$ & $145(1.5)$ & $680(6.8)$ & 8850 (88.5) \\
\hline Most deprived & $170(2.0)$ & $345(4.0)$ & $165(1.9)$ & $825(9.6)$ & 7110 (82.5) \\
\hline \multicolumn{6}{|l|}{ NZ individual deprivation } \\
\hline 0 & $55(0.2)$ & $155(0.4)$ & $140(0.4)$ & $1020(2.9)$ & 34205 (96.1) \\
\hline $1-2$ & $150(1.4)$ & 370 (3.6) & $210(2.0)$ & 1170 (11.3) & $8455(81.7)$ \\
\hline $3-7$ & $260(8.7)$ & 375 (12.7) & $135(4.6)$ & $690(23.4)$ & $1495(50.5)$ \\
\hline \multicolumn{6}{|l|}{ Highest qualification } \\
\hline Degree or higher & $50(0.7)$ & $60(0.8)$ & $50(0.7)$ & $305(4.1)$ & $6990(93.8)$ \\
\hline No qualification & $135(1.2)$ & $260(2.3)$ & $150(1.3)$ & $765(6.8)$ & 9910 (88.3) \\
\hline School qualification & $85(0.6)$ & $205(1.6)$ & $125(1.0)$ & $760(5.9)$ & $11810(90.9)$ \\
\hline Vocational qualification & $195(1.1)$ & $370(2.1)$ & $160(0.9)$ & $1055(6.1)$ & 15435 (89.7) \\
\hline \multicolumn{6}{|l|}{ Age, in years } \\
\hline $15-24$ & $75(1.0)$ & $155(2.0)$ & $145(1.8)$ & $545(6.9)$ & $6975(88.3)$ \\
\hline $25-64$ & $375(1.1)$ & $715(2.1)$ & $320(1.0)$ & $2245(6.7)$ & 29665 (89.0) \\
\hline$>64$ & $10(0.1)$ & $30(0.4)$ & $20(0.3)$ & $95(1.2)$ & 7510 (98.0) \\
\hline \multicolumn{6}{|l|}{ Sex } \\
\hline Male & $130(0.6)$ & $235(1.1)$ & $170(0.8)$ & $935(4.2)$ & 20820 (93.4) \\
\hline Female & 330 (1.2) & $665(2.5)$ & 320 (1.2) & 1950 (7.3) & 23335 (87.7) \\
\hline \multicolumn{6}{|l|}{ Ethnicity } \\
\hline $\mathrm{nMnPnA}$ & $285(0.7)$ & $550(1.4)$ & $265(0.7)$ & $1965(5.0)$ & 35985 (92.2) \\
\hline Māori & $130(2.4)$ & 215 (3.9) & $135(2.4)$ & $580(10.5)$ & 4435 (80.8) \\
\hline Pacific & $40(2.1)$ & $105(5.4)$ & $75(3.7)$ & 250 (12.8) & $1480(76.0)$ \\
\hline Asian & $10(0.3)$ & $30(1.2)$ & $20(0.8)$ & $90(3.7)$ & 2255 (93.8) \\
\hline \multicolumn{6}{|c|}{$\begin{array}{l}\text { Total counts are rounded means. } \\
\text { *Two non-collections in two waves or three non-collections in three waves. } \\
\text { tTwo non-collections in three waves. } \\
\text { fOne non-collection in two waves. } \\
\text { §One non-collection in three waves. } \\
\text { INo non-collections in two or three waves. } \\
\text { nMnPnA, non-Māori non-Pacific non-Asian; SoFIE, Survey of Family, Income, and Employment. }\end{array}$} \\
\hline
\end{tabular}

household composition, labour force status). To our knowledge, this is the first longitudinal study to specifically examine the association between cost-related noncollection of prescription items and health, net of all but unknown time-varying confounders. The main limitation with fixed effects analysis is that these models do not allow for either the effect of current health on future prescription collection status (reverse causation), or past health on future health (state dependence), which violate the strict exogeneity condition required by fixed effects methods. ${ }^{32} 33$ Additionally, our analyses may be affected by selection bias if those who dropped out from the study reported substantially more or less deferral. However, we found no evidence that exposureoutcome associations differed between those who contributed information to two or three waves. If those who dropped out from the study before wave 3 or contributed to only one of waves 3,5 , or 7 were more likely to 
Table 3 Empirical transition probabilities (\%) computed from counts of the number of times respondents reported the indicated pair of prescription collection states in successive observations over 3 waves

\begin{tabular}{lll}
\hline & \multicolumn{2}{l}{ To (wave w+2) } \\
\cline { 2 - 3 } From $(w)$ & Collection & Non-Collection \\
\hline Collection & 97.4 & 2.6 \\
Non-Collection & 68.8 & 31.2 \\
\hline
\end{tabular}

Transition probabilities were derived by dividing these counts by row totals.

Transition probabilities between the same states are shown in bold.

report non-collection of prescription medication, then the true population relationship between prescription deferral and declining health would be stronger than found in this study. However, the collection-health relationship in these 'drop-outs' would need to be very different to the 'stay-ins' to change our conclusions. As with other self-reported surveys, health status is measured using self-reported data that rely on the ability of respondents to recall information accurately. While SRH is widely used in the social sciences, and is a wellestablished and reliable instrument in cross-sectional studies, ${ }^{34}{ }^{35}$ its longitudinal reliability is less well-studied. Thus in longitudinal studies, SRH may suffer from a variety of biases, including measurement error, for example, from ceiling effects. ${ }^{33}$

\section{Strengths and weaknesses in relation to other studies}

As mentioned in the introduction, few previous studies have considered the health impact of not collecting prescription drugs. Even fewer have provided longitudinal evidence. This work extends findings from the previous longitudinal study of Heisler et al, ${ }^{16}$ which had only middle-aged or older adults and a shorter follow-up. Our study included the total adult population over 15 years of age and had a longer follow-up (5 years). Moreover, in Heisler et $a l^{16}{ }^{16}$ over half of those who restricted medicine use because of cost had no insurance coverage for medicines and therefore are likely to have faced far higher prescription costs than those in our study.

Our finding that non-collection of prescriptions had a more significant effect on the health of males than females, particularly in terms of mental health, has not been reported previously. Another study using the same data set found food insecurity had greater impacts on mental health among women. ${ }^{36}$ Usually, females consult general practitioners more frequently and take more prescription medicines. ${ }^{37} 38$ It is possible that, on average, the medicines that males take are more crucial to maintaining their health status in the short to medium term, and therefore deferral has a more dramatic effect. An alternative interpretation could be that, within households, medicines for men are prioritised over those for women. Such a pattern has been reported for food within households in some developing countries. ${ }^{39}$ If this is the case, then not being able to afford men's medicines may indicate more severe financial hardship. Further research is needed to confirm this finding and explore these interpretations.

In our study, non-collection of prescription medicines did not result in a decline in self-reported health among elderly people, unlike Heisler $e t a l .{ }^{16}$ Non-collection of a prescription item due to cost seems to be relatively uncommon among the elderly in New Zealand (2\% in this study), probably because universal superannuation ensures relatively low rates of poverty among the elderly. ${ }^{40}$ Non-collection of prescription medication could, therefore, be less commonly experienced by those elderly people, making the effect on health harder to measure, or perhaps high levels of prescribing to the elderly means that drugs that do not affect their (self-rated) health can be deferred. ${ }^{41}$ In contrast, rates of poverty among young people (15-24 years) and the working age population (25-64 years) are higher, ${ }^{42}$ and people in these age groups are likely to face higher charges for primary care. During the study period, extrafunding was provided to primary health organisations to reduce fees for those aged over 65 years from 2004, while for those 18-65 years of age, the fee reduction was introduced in tranches from 2005 to $2007 .^{43}$ Therefore, younger people who do not collect all their prescriptions may defer more of them than elderly who do not collect all of theirs.

\section{Meaning of the study}

The study findings increase understanding of the importance of cost-related non-collection of prescription drugs in the context of addressing and improving the health of the population. Given the importance of prescription medication in maintaining health and treatment of acute and chronic illness, it is important to design a co-payment regime that ensures that prescriptions are affordable. Copayments in New Zealand are low by international standards and the majority in each of the waves did not report cost affecting not-collection of prescription items. However, for the relatively small subset of the population who did have to defer prescription items, this resulted in poorer health. While only a small proportion of the population reported noncollection of prescription items due to cost, reporting this in one wave means that there was a reasonable probability $(31.2 \%$, table 3$)$ of reporting it again in the next wave. This suggests that some people were repeatedly unable to afford their prescriptions and, as discussed previously in relation to table 1 , were therefore likely to experience increasing ill-effects on their health. Ensuring access to prescription medicines for this group needs attention. While it is encouraging that in a publicly-funded system only a small proportion of the population was not collecting prescription medication, it is important to note that even small prescription 
Table 4 Estimates with 95\% Cls from linear fixed effects regression models for three health outcomes

\begin{tabular}{|c|c|c|c|c|c|c|}
\hline \multirow[b]{2}{*}{ Characteristics } & \multicolumn{2}{|l|}{ SRH } & \multicolumn{2}{|l|}{ PCS } & \multicolumn{2}{|l|}{ MCS } \\
\hline & Estimate (Cl) & $p$ Value & Estimate (Cl) & $p$ Value & Estimate (Cl) & $p$ Value \\
\hline \multicolumn{7}{|l|}{ Collection status } \\
\hline Collection & 1 & & 1 & & 1 & \\
\hline Non-collection & 0.11 (0.07 to 0.15$)$ & 0.00000 & $-1.00(-1.40$ to -0.61$)$ & 0.00000 & $-1.69(-2.18$ to -1.19$)$ & 0.00000 \\
\hline \multicolumn{7}{|l|}{ Wave } \\
\hline 3 & 1 & & 1 & & 1 & \\
\hline 5 & 0.07 (0.05 to 0.08$)$ & 0.00000 & $0.03(-0.11$ to 0.16$)$ & 0.70634 & 0.24 (0.08 to 0.41$)$ & 0.00488 \\
\hline 7 & $0.16(0.14$ to 0.17$)$ & 0.00000 & $-0.66(-0.80$ to -0.51$)$ & 0.00000 & 0.23 (0.05 to 0.41$)$ & 0.01194 \\
\hline \multicolumn{7}{|l|}{ Marital status } \\
\hline Never married & 1 & & 1 & & 1 & \\
\hline Previously married & $-0.02(-0.08$ to 0.05$)$ & 0.62482 & $-0.56(-1.16$ to 0.05$)$ & 0.07313 & $-0.80(-1.55$ to -0.04$)$ & 0.03903 \\
\hline Married & $0.00(-0.05$ to 0.06$)$ & 0.88864 & $-0.82(-1.35$ to -0.30$)$ & 0.00224 & 0.75 (0.10 to 1.40$)$ & 0.02466 \\
\hline \multicolumn{7}{|l|}{ Family type } \\
\hline Couple only & 1 & & 1 & & 1 & \\
\hline One person & $0.01(-0.03$ to 0.06$)$ & 0.62878 & $0.18(-0.26$ to 0.62$)$ & 0.42776 & $-0.30(-0.85$ to 0.24$)$ & 0.27493 \\
\hline Sole parent & $-0.04(-0.10$ to 0.03$)$ & 0.24965 & $0.76(0.15$ to 1.38$)$ & 0.01517 & $-0.23(-0.99$ to 0.53$)$ & 0.56022 \\
\hline Couple with children & $-0.01(-0.05$ to 0.02$)$ & 0.48955 & $0.05(-0.29$ to 0.40$)$ & 0.76646 & $-0.06(-0.49$ to 0.37$)$ & 0.78074 \\
\hline \multicolumn{7}{|l|}{ Labour force status } \\
\hline Employed & 1 & & 1 & & 1 & \\
\hline Not employed & 0.05 (0.03 to 0.08$)$ & 0.00018 & $-0.71(-0.97$ to -0.44$)$ & 0.00000 & $-0.77(-1.10$ to -0.44$)$ & 0.00000 \\
\hline \multicolumn{7}{|l|}{ NZDep (deprived) } \\
\hline Least & 1 & & 1 & & 1 & \\
\hline Middle & $-0.02(-0.06$ to 0.01$)$ & 0.20890 & $0.23(-0.12$ to 0.58$)$ & 0.19233 & $-0.13(-0.57$ to 0.30$)$ & 0.55401 \\
\hline Most & $0.03(-0.01$ to 0.07$)$ & 0.18671 & $-0.06(-0.48$ to 0.36$)$ & 0.79575 & $-0.56(-1.08$ to -0.04$)$ & 0.03667 \\
\hline \multicolumn{7}{|l|}{ NZiDep (dep) } \\
\hline 0 & 1 & & 1 & & 1 & \\
\hline $1-2$ & 0.06 (0.03 to 0.08$)$ & 0.00000 & $-0.12(-0.34$ to 0.10$)$ & 0.28342 & $-1.27(-1.54$ to -0.99$)$ & 0.00000 \\
\hline $3-7$ & $0.13(0.09$ to 0.17$)$ & 0.00000 & $-0.64(-1.07$ to -0.21$)$ & 0.00363 & $-3.24(-3.77$ to -2.71$)$ & 0.00000 \\
\hline \multicolumn{7}{|l|}{ Education } \\
\hline Degree or higher & 1 & & 1 & & 1 & \\
\hline No education & $0.02(-0.09$ to 0.12$)$ & 0.74736 & $-0.66(-1.66$ to 0.34$)$ & 0.20022 & $0.40(-0.84$ to 1.65$)$ & 0.52918 \\
\hline School & $0.05(-0.03$ to 0.14$)$ & 0.22827 & $-0.17(-0.99$ to 0.65$)$ & 0.69131 & $-0.72(-1.74$ to 0.29$)$ & 0.16528 \\
\hline Postschool & $0.02(-0.07$ to 0.11$)$ & 0.69048 & $0.06(-0.81$ to 0.93$)$ & 0.89149 & $0.01(-1.07$ to 1.10$)$ & 0.97857 \\
\hline
\end{tabular}

Main exposure was prescription collection status. $p$ Values represent the significance of each covariate level.

MCS, mental health score; PCS, physical health score; SRH, self-rated health. 
charges can have a deleterious effect on health. In Quebec, Canada, the public insurer has eliminated co-payments for people on low incomes and, as a result, such people are more likely to pick up prescription medicines. ${ }^{44}$

Governments and insurance companies in many countries are battling with increasing prescription medicine expenditure. One common response has been to shift costs on to patients and at the same time to discourage 'unnecessary' use by increasing prescription charges. ${ }^{75-47}$ This study's finding that even very modest prescription charges lead to non-collection of prescription medication that is associated with a measurable decline in health status should be weighed against the modest income the New Zealand government generates from such charges. The New Zealand Treasury estimated the recent increase in prescription charges from $\$ 3$ to $\$ 5$ could lead to an additional \$45-50 million in revenue. ${ }^{48}$ Their discussion of the costs and benefits did not include any potential negative health outcomes from increasing charges: this study shows that these could be significant. The increase in revenue from an increase in copayments has to be weighed against the evidence that higher copayment for prescription drugs leads to reduction in demand for pharmaceuticals (and/or increase in non-collection of prescription medication) with a simultaneous increase in the demand for acute care ${ }^{49}$ which may be more costly. Even a marginal increase in non-collection of prescription medication is likely to increase rates of poor health (and in a public health system, higher costs for treatment elsewhere). For example, Tamblyn et $a l^{8}$ found significant increases in serious adverse events and emergency department visits among elderly people and welfare recipients after the introduction of cost-sharing in Quebec, Canada. The additional revenue generated by an increase in prescription charges could be partly or wholly offset by the cost increase associated with higher hospitalisation and demand for acute care.

\section{Unanswered questions and future research}

First, our study did not ask about the perceived need or type of medication that was deferred because of cost. Second, this study did not identify other reasons for deferring prescription medicines, such as geographical distance, or the cost of medical care for other family members. Future research should also look at the accumulated exposure to non-collection, that is, how many prescription items or how many times one needs to not collect prescription medication for it to have an effect on health. More general models (eg, g-method estimators) can provide unbiased results when there are complex dynamics of evolving exposures and outcomes ${ }^{50-52}$ but such methods are beyond the scope of this analysis, which focused on the association between health and deferral of prescriptions net of measured time-varying and unmeasured time-invariant confounding.
Author affiliations

${ }^{1}$ Alfred Deakin Institute for Citizenship \& Globalisation, Deakin University Waterfront Campus, Geelong, Victoria, Australia

${ }^{2}$ Department of Public Health, Wellington School of Medicine and Health Sciences, University of Otago, Wellington, New Zealand

${ }^{3}$ School of Pharmacy, University of Otago, Dunedin, New Zealand

${ }^{4}$ University of Otago, Dunedin, New Zealand

Contributors SJ conceived the study and planned the analyses, interpretation and drafting of the paper. KR led the analyses, and contributed to interpretation and drafting of the article. PN and PC contributed to drafting of the article. All the authors approved the final version.

Funding This work was supported by Health Research Council of New Zealand grant number 08/048.

Competing interests All the authors have completed the ICMJE uniform disclosure form at http://www.icmje.org/coi_disclosure.pdf (available on request from the corresponding author) and declare: no support from any organisation for the submitted work; no financial relationships with any organisations that might have an interest in the submitted work in the previous 3 years; no other relationships or activities that could appear to have influenced the submitted work.

Ethics approval University of Otago Human Ethics Committee.

Provenance and peer review Not commissioned; externally peer reviewed.

Data sharing statement The SoFIE-Health unit record data are available to bona fide researchers (on application and approval) in the data laboratory at Statistics NZ.

Open Access This is an Open Access article distributed in accordance with the Creative Commons Attribution Non Commercial (CC BY-NC 4.0) license, which permits others to distribute, remix, adapt, build upon this work noncommercially, and license their derivative works on different terms, provided the original work is properly cited and the use is non-commercial. See: http:// creativecommons.org/licenses/by-nc/4.0/

Statistics New Zealand Security Statement Access to the data used in this study was provided by Statistics New Zealand in a secure environment designed to give effect to the confidentiality provisions of the Statistics Act, 1975. The results in this study and any errors contained therein are those of the authors, not Statistics New Zealand.

Disclaimer Opinions expressed in this paper are those of the authors only and do not necessarily represent the views of peer reviewers or the University of Otago.

\section{REFERENCES}

1. Manning W, Newhouse J, Duan N, et al. Health insurance and the demand for medical care: results from a randomized experiment. Santa Monica: Rand, 1988.

2. Ess SM, Schneeweiss S, Szucs TD. European healthcare policies for controlling drug expenditure. Pharmacoeconomics 2003;21:89-103.

3. Danzon PM, Furukawa MF. Prices and availability of pharmaceuticals: evidence from nine countries. Health Aff (Millwood) 2003;Suppl Web Exclusives:W3-521-36.

4. Noyce PR, Huttin C, Atella V, et al. The cost of prescription medicines to patients. Health Policy 2000;52:129-45.

5. Krobot KJ, Miller WC, Kaufman JS, et al. The disparity in access to new medication by type of health insurance: lessons from Germany. Med Care 2004;42:487-91.

6. Goldman D, Joyce G, Zheng Y. Prescription drug cost sharing: associations with medication and medical utilization and spending and health. JAMA 2007;298:61-9.

7. Joyce G, Escarce J, Solomon M, et al. Employer drug benefit plans and spending on prescription drug. JAMA 2002;288:1733-9.

8. Tamblyn R, Laprise R, Hanley JA, et al. Adverse events associated with prescription drug cost-sharing among poor and elderly persons JAMA 2001;285:421-9.

9. Lexchin J, Grootendorst P. Effects of prescription drug user fees on drug and health services use and on health status in vulnerable populations: a systematic review of the evidence. Int J Health Serv 2004;34:101-22.

10. Mojtabai R, Olfson M. Medication costs, adherence, and health outcomes among Medicare beneficiaries. Health Aff (Millwood) 2003;22:220-9. 
11. Kennedy J, Erb C. Prescription noncompliance due to cost among adults with disabilities in the United States. Am J Public Health 2002;92:1120-4.

12. Piette JD, Heisler M, Wagner TH. Problems paying out-of-pocket medication costs among older adults with diabetes. Diabetes Care 2004;27:384-91.

13. Piette JD, Wagner T, Potter M, et al. Health insurance status, cost-related medication underuse, and outcomes among diabetes patients in three systems of care. Med Care 2004;42:102-9.

14. Adams AS, Soumerai SB, Ross-Degnan D. The case for a medicare drug coverage benefit: a critical review of the empirical evidence. Annu Rev Public Health 2001;22:49-61.

15. Schoen MD, DiDomenico RJ, Connor SE, et al. Impact of the cost of prescription drugs on clinical outcomes in indigent patients with heart disease. Pharmacotherapy 2001;21:1455-63.

16. Heisler M, Langa KM, Eby EL, et al. The health effects of restricting prescription medication use because of cost. Med Care 2004;42:626-34.

17. Heisler M, Choi H, Rosen A, et al. Hospitalizations and deaths among adults with cardiovascular disease who underuse medications because of cost: a longitudinal anlaysis. Med Care 2010;48:87-94.

18. Medicare.gov: The official US government site for Medicare: Costs in the coverage gap. http://www.medicare.gov/part-d/costs/coveragegap/part-d-coverage-gap.html.

19. Patient.co.uk. Free or reduced cost prescriptions. http://www.patient. co.uk/health/free-or-reduced-cost-prescriptions

20. Appleby J. Prescription charges: are they worth it? BMJ 2014;348: g3944.

21. Jatrana $S$, Crampton $P$, Norris $P$. Ethnic differences in access to prescription medication because of cost in New Zealand. J Epidemiol Community Health 2011;65:454-60.

22. Carter K, Cronin M, Blakely T, et al. Cohort Profile: survey of Families, Income and Employment (SoFIE) and health extension (SoFIE-Health). Int J Epidemiol 2010;39:653-9.

23. Statistics New Zealand. Survey of Family, Income, and Employment (SoFIE). 2011. http://www.stats.govt.nz/sofie

24. Cohen S, Kamarck T, Mermelstein R. A global measure of perceived stress. J Health Soc Behav 1983;24:385-96.

25. Coons SJ, Rao S, Keininger DL, et al. A comparative review of generic quality-of-life instruments. Pharmacoecomomics 2000;17:13-35.

26. Hemingway $\mathrm{H}$, Stafford M, Stansfeld S, et al. Is the SF-36 a valid measure of change in population health? Results from the Whitehall II Study. BMJ 1997;315:1273-9.

27. Scott KM, Tobias MI, Sarfati D, et al. SF-36 health survey reliability, validity and norms for New Zealand. Aust N Z J Public Health 1999;23:401-6.

28. Ware J, Kosinski M. SF-36 Physical and Mental Health Summary Scales: A Manual for Users of Version 1. SF-36 Physical and Mental Health Summary Scales: A Manual for Users of Version 1.

29. Salmond C, Crampton P. The development of New Zealand's deprivation index (NZDep) and its uptake as a national policy tool. Can J Public Health 2012;103(8 Suppl 2):S7-11.

30. Salmond C, King P, Crampton P, et al. NZiDep: a New Zealand index of socioeconomic deprivation for individuals. Soc Sci Med 2006;62:1474-85.

31. Allison PD. Fixed effects regression methods for longitudinal data: using SAS. SAS Publishing, 2005.

32. Wooldridge J. Econometric analysis of cross section and panel data. Cambridge, MA: MIT Press, 2002.

33. Gunasekara FI, Carter K, Blakely T. Comparing self-rated health and self-assessed change in health in a longitudinal survey: which is more valid? Soc Sci Med 2012;74:1117-24.
34. Idler EL, Benyamini Y. Self-rated health and mortality: a review of twenty-seven community studies. J Health Soc Behav 1997;38:21-37.

35. Lopez R. Income inequality and self-rated health in US metropolitan areas: a multi-level analysis. Soc Sci Med 2004;59:2409-19.

36. Carter KN, Kruse K, Blakely $\mathrm{T}$, et al. The association of food security with psychological distress in New Zealand and any gender differences. Soc Sci Med 2011;72:1463-71.

37. Ministry of Health. New Zealand Health Survey: annual update of key findings 2012/13. Wellington, New Zealand, 2013. http://www. health.govt.nz/publication/new-zealand-health-survey-annual-updatekey-findings-2012-13

38. Thorell K, Skoog J, Zielinski A, et al. Licit prescription drug use in a Swedish population according to age, gender and socioeconomic status after adjusting for level of multi-morbidity. BMC Public Health 2012;12:575.

39. Food and Agriculture Organisation (FAO), Asian Development Bank (ADB). Gender equality and food security: women's empowerment as a tool against hunger. Mandaluyong City, Manila, Philippines: Asian Development Bank, 2013.

40. Stephens C, Alpass F, Towers A. Economic hardship among older people in New Zealand: the effects of low living standards on social support, loneliness, and mental health. $N Z$ J Psychol 2010;39:49-55

41. Tordoff JM, Bagge ML, Gray AR, et al. Medicine-taking practices in community-dwelling people aged $\geq 75$ years in New Zealand. Age Ageing 2010;39:574-80.

42. Perry B. Household incomes in New Zealand: trends in indicators of inequality and hardship 1982 to 2013. Wellington: Ministry of Social Development, 2014

43. Cumming J, Raymont A, Gribben B, et al. Evaluation of the Implementation and Intermediate Outcomes of the Primary Health Care Strategy First Report: Overview. Wellington, 2005. http://www. health.govt.nz/our-work/primary-health-care/research-andevaluation-primary-health-care-initiatives\#evaluation (accessed 23 Oct 2014).

44. Tamblyn R, Eguale T, Huang A, et al. The incidence and determinants of primary nonadherence with prescribed medication in primary care: a cohort study. Ann Intern Med 2014;160:441-50.

45. Austvoll-Dahlgren A, Aaserud M, Vist G, et al. Pharmaceutical policies: effects of cap and co-payment on rational drug use (review). Cochrane Database Syst Rev 2008;(1):CD007017.

46. Aaltonen $\mathrm{K}$, Niemelä $\mathrm{M}$, Norris $\mathrm{P}$, et al. Trends and income related differences in out-of-pocket costs for prescription and over-thecounter medicines in Finland from 1985 to 2006. Health Policy 2013;110:131-40.

47. Hynd A, Roughead EE, Preen DB, et al. The impact of co-payment increases on dispensings of government-subsidised medicines in Australia. Pharmacoepidemiol Drug Saf 2008;17:1091-9.

48. The Treasury. Budget 2012 Information Release. http://www. treasury.govt.nz/publications/informationreleases/budget/2012. June 2012.

49. Horn SD, Sharkey PD, Tracy DM, et al. Intended and unintended consequences of $\mathrm{HMO}$ cost-containment strategies: results from the managed care outcomes project. Am J Manag Care 1996;2: 253-64.

50. Greenland S, Robins J. Identifiability, exchangeability and confounding revisited. Epidemiol Perspect Innov 2009;6:4.

51. Pearl J. Causality: models, reasoning, and inference (2nd ed). New York: Cambridge University Press, 2009.

52. Robins J, Hernán M. Estimation of the causal effects of time-varying exposures. In: Fitzmaurice G, Davidian M, Verbeke G, et al., eds. Longitudinal data analysis. Boca Raton: CR Press Taylor and Francis Group, 2009:553-99. 